\title{
Antipyrine clearance during experimental and occupational exposure to toluene
}

\author{
M DøSSING, J BAELUM, AND G R LUNDQVIST
}

From Medical Department A, Division of Hepatology, Rigshospitalet, DK-2100 Copenhagen, and Hygienic Institute, University of Arhus, DK-8000 Arhus, Denmark

ABSTRACT Exposure to toluene vapour enhances hepatic microsomal enzyme function in animals as assessed by the metabolism of the test drug antipyrine. Thirty six printing trade workers with long term occupational exposure to a mixture of organic solvents and 39 matched controls were randomly allocated into four groups. Eighteen printers and 21 controls were exposed to $100 \mathrm{ppm}$ of toluene during 6.5 hours in an exposure chamber. The remaining 18 printers and 18 controls were exposed to $0 \mathrm{ppm}$ of toluene under similar conditions. The salivary clearance of antipyrine was measured immediately after the stay in the exposure chamber to investigate a possible acute change in liver function and was repeated two weeks later, shortly before the summer vacation. Antipyrine clearance was measured again at the end of the summer vacation-four weeks after exposure. To study a possible effect of chronic exposure on antipyrine clearance 12 printing trade workers with 17 years (median) of occupational exposure to toluene vapour at concentrations of about $100 \mathrm{ppm}$ were investigated before and four weeks after cessation of exposure. No difference in antipyrine clearance was found either within the groups or between the groups at any of the measurements.

Toluene is extensively used in a variety of industrial processes, and an increasing number of workers are exposed to its vapour. ${ }^{1}$

Animal experiments have shown that toluene is biotransformed in the microsomal enzyme system of the liver, ${ }^{2-4}$ and that toluene vapour increases the microsomal enzyme activity of the liver in rats as assessed by the clearance of antipyrine and by quantitative measurements of hepatic cytochrome p-450 enzyme system..$^{45}$ Changes in hepatic microsomal enzyme function in man may lead to changes in the biotransformation of hormones, drugs, and other chemicals that are metabolised in this enzyme system. ${ }^{67}$

Antipyrine is widely used as a model drug for quantitative assessment of hepatic microsomal enzyme function in man, ${ }^{8}$ and in the present study antipyrine clearance was measured in groups of workers acutely or chronically exposed to toluene vapour to assess a possible change in microsomal liver function.

Received 24 May 1982

Accepted 12 October 1982

\section{Materials and methods}

The study was performed on two different series of subjects. One aimed at studying the effects of acute exposure to toluene and the subjects were printing trade workers occupationally exposed to a mixture of solvents including toluene (exposure group 1) and a matched control group. The second series consists of printers occupationally exposed only to toluene (exposure group 2).

The exposure groups were selected in cooperation with the trade unions. Group 1 came from six printing plants where air analysis had been performed regularly during the three years before the study and group 2 from a plant where toluene was the only solvent used in cleaning operations; air analyses covering the past eight years were available.

Three hundred subjects were drawn from the central person register and matched with the printing trade workers from exposure group 1 according to age, education (skilled/unskilled workers), smoking habits and place of residence (town/suburb/ country). Workers with occupational exposure to chemical agents were excluded from the control group. 
Exclusion criteria for all subjects included liver, kidney, and other disabling diseases, allergic disorders including drug reactions, more than 15 days of absence from work during the past year, regular drug intake, use of any drug during the 14 days before the study, and an average daily alcohol consumption exceeding four drinks ( $>50 \mathrm{~g}$ ethanol).

Forty eight printing trade workers ( 36 in group 1 and 12 in group 2) and 39 controls fulfilled the inclusion criteria, and all gave informed consent.

No difference was found in bodyweight and height, and daily consumption of tobacco, alcohol, and coffee/tea between the groups.

\section{OCCUPATIONAL EXPOSURE}

Exposure group 1-The workers were exposed daily to a mixture of organic solvents, mainly toluene. During the years before the study toluene had gradually been replaced by other solvents such as ethylacetate and ethanol. The recorded exposure levels of organic solvents ranged from $0 \cdot 1$ to $1 \cdot 1$ times the sum of the measured time weighted average concentrations divided by the respective maximal allowed time weighted average concentrations. The concentration of toluene ranged from 10 to 30 ppm. The workers had worked as printers for 15 years median (range 8-25).

Exposure group 2-Air concentrations of toluene collected on charcoal tubes had been measured about 200 times a year during the eight years before the study. The concentrations were $125(0-350), 100$ $(70-400), 120(40-910), 60(15-350), 100(10-$ $300), 105(30-400)$, and $100(30-450) \mathrm{ppm}$, median (range); thus the concentration of toluene had been about $100 \mathrm{ppm}$ all through the years $1974-81$. The workers had been employed at the plant for 17 years median (range 5-37).

\section{EXPERIMENTAL EXPOSURE}

Only exposure group 1 and the control group participated in this part of the study. Each matched pair of subjects was randomly exposed to $100 \mathrm{ppm}$ or $0 \mathrm{ppm}$ toluene for $6 \cdot 5$ hours in a controlled exposure chamber after undergoing a medical examination.

The exposure chamber is described in detail elsewhere. ${ }^{9}$ The concentration of toluene was $102 \pm 2$ ppm (mean $\pm \mathrm{SD}$ ) during exposure, and below $0 \cdot 1$ ppm during the control experiment. While in the exposure chamber under the control of a doctor, neuropsychological and lung function tests were performed, the results of which are given elsewhere. ${ }^{9}$

\section{ANTIPYRINE TEST}

Immediately after the experimental exposure and three hours after the last meal, $5 \mathrm{ml}$ of saliva was collected before, and 3, 5, 7-10, 15-19, and 19-31 hours after an oral dose of $1 \mathrm{~g}$ antipyrine in $10 \%$ solution diluted with water. The antipyrine measurement was repeated two weeks later (shortly before the summer vacation) at the end of four weeks free from exposure (summer vacation), and finally four weeks after resuming work. The printing trade workers in exposure group 2 were investigated before and four weeks after cessation of exposure. The antipyrine test and clearance calculation were performed as previously described. ${ }^{1011}$

The reliability of the antipyrine measurements performed by the subjects themselves was assessed as the residual variance around the regression line of the log saliva concentration $v$ time of 25 randomly drawn antipyrine measurements from 25 of those investigated. The median residual variance was $4.2 \%$ of the mean clearance of antipyrine (range $0 \cdot 7-14.8 \%$ ), which does not significantly differ from that of similar measurements in 25 subjects where antipyrine administration and sample collection had been performed by laboratory technicians (median residual variance: $4 \cdot 0 \%$ (range $0 \cdot 6-16 \cdot 7 \%$ )).

Before and after experimental exposure to toluene a venous blood sample was drawn, from which plasma was separated by centrifugation and stored at $-70^{\circ} \mathrm{C}$ until analysed. Serum gammaglutamyltransferase (s- $\gamma \mathrm{GT})$ was estimated in all samples, whereas serum alanine aminotransferase (s-ALAT), serum aspartate aminotransferase (s-ASAT), and serum alkaline phosphatase were estimated from the first sample only.

Differences within groups were calculated by Wilcoxon's rank sum test for paired observations or a paired $t$ test when data were considered normally distributed (the antipyrine data). Comparisons between groups were conducted with the corresponding non-paired tests. $p<0.05$ was considered statistically significant.

\section{Results}

No change in the clearance of antipyrine was observed within the groups, neither during the acute experimental exposure nor during the exposure free period of four weeks (tables 1 and 2). No difference was found between the groups.

The inter-individual difference assessed as the percentage deviation from the mean of each measurement in the groups was $15.7 \%$ to $21.7 \%$ (median), and ranged from $0.0 \%$ to $112.7 \%$. The intra-individual deviation from the average of the four measurements was calculated in each individual. The median intra-individual deviation in each group at the four measurements ranged from $5.7 \%$ to $11.6 \%$. The lowest and highest deviation in one individual at one of the measurements were 
Table 1 Acute exposure to toluene. Antipyrine clearance in printing trade workers of exposure group 1 and controls immediately after experimental exposure to $100 \mathrm{ppm}$ or 0 ppm toluene for 6.5 hours (measurement 1) and two weeks later (measurement 2) when the workers were exposed to a mixture of organic solvents including toluene at work

\begin{tabular}{|c|c|c|c|c|c|c|c|}
\hline \multirow[b]{3}{*}{$\begin{array}{l}\text { Exposure group } 1 \\
(n=36)\end{array}$} & \multirow{3}{*}{$\begin{array}{l}\text { Dose of toluene } \\
\text { (ppm) } \\
\begin{array}{c}100 \\
0\end{array}\end{array}$} & \multicolumn{6}{|c|}{ Antipyrine clearance $\left(\operatorname{ml} \times \min ^{-1}\right)$} \\
\hline & & \multirow{2}{*}{$\begin{array}{c}\text { No } \\
17 \\
17\end{array}$} & \multicolumn{2}{|c|}{$\begin{array}{l}\text { Measurement } 1 \\
\text { Mean (SD) }\end{array}$} & \multirow{2}{*}{$\begin{array}{c}\text { No } \\
16 \\
16\end{array}$} & \multicolumn{2}{|c|}{$\begin{array}{l}\text { Measurement } 2 \\
\text { Mean (SD) }\end{array}$} \\
\hline & & & $\begin{array}{l}57 \cdot 4 \\
58 \cdot 8\end{array}$ & $\begin{array}{r}(9 \cdot 4) \\
(12 \cdot 2)\end{array}$ & & $\begin{array}{l}52 \cdot 2 \\
54 \cdot 1\end{array}$ & $\left(\begin{array}{l}16 \cdot 0) \\
18 \cdot 8)\end{array}\right.$ \\
\hline $\begin{array}{l}\text { Control group } \\
(n=39)\end{array}$ & $\begin{array}{r}100 \\
0\end{array}$ & $\begin{array}{l}21 \\
18\end{array}$ & $\begin{array}{l}61: 5 \\
54 \cdot 5\end{array}$ & $(17 \cdot 5)$ & $\begin{array}{l}18 \\
18\end{array}$ & $\begin{array}{l}58 \cdot 7 \\
48 \cdot 3\end{array}$ & $\left\{\begin{array}{l}21 \cdot 5) \\
11 \cdot 9)\end{array}\right.$ \\
\hline
\end{tabular}

Table 2 Chronic exposure to toluene. Antipyrine clearance among printing trade workers with occupational exposure to a mixture of organic solvents (exposure group 1) and workers chronically exposed to toluene at work (exposure group 2) measured during and four weeks after exposure. The control group was investigated with the same time interval

\begin{tabular}{|c|c|c|c|c|c|c|}
\hline \multirow[b]{3}{*}{$\begin{array}{l}\text { Exposure group } 1 \\
(\mathrm{n}=36)\end{array}$} & \multirow{3}{*}{\begin{tabular}{|l} 
No \\
32
\end{tabular}} & \multicolumn{5}{|c|}{ Antipyrine clearance $\left(m l \times \min ^{-1}\right)$} \\
\hline & & \multicolumn{2}{|c|}{$\begin{array}{l}\text { During exposure } \\
\text { mean }(S D)\end{array}$} & \multirow{2}{*}{$\begin{array}{l}\text { No } \\
32\end{array}$} & \multicolumn{2}{|c|}{$\begin{array}{l}\text { Free from exposure } \\
\text { mean }(S D)\end{array}$} \\
\hline & & $53 \cdot 1$ & $(17 \cdot 2)$ & & $60 \cdot 2$ & $(15 \cdot 2)$ \\
\hline $\begin{array}{l}\text { Exposure group } 2 \\
(n=12)\end{array}$ & 12 & $55 \cdot 2$ & $(10 \cdot 0)$ & 12 & $58 \cdot 3$ & $(14 \cdot 4)$ \\
\hline $\begin{array}{l}\text { Control group } \\
(\mathbf{n}=39)\end{array}$ & 36 & 53.6 & $(18 \cdot 0)$ & 29 & $54 \cdot 4$ & $(13 \cdot 1)$ \\
\hline
\end{tabular}

$0.0 \%$ and $54.2 \%$, respectively. The inter- and intra-individual variation among the groups was equal at the three measurements.

Antipyrine clearance among the smokers was significantly higher $(15 \%, 28 \%, 19 \%$, and $20 \%$ at the four measurements, respectively) than antipyrine clearance of the non-smokers $(p<0.05, t$ test).

There was no difference in s-ASAT, s-ALAT, $s-\gamma \mathrm{GT}$, or s-alkaline phosphatase between the exposure groups and the control workers ( $p>0.2)$.

\section{Discussion}

This study shows that neither acute exposure to 100 ppm toluene during a "working day" (6.5 hours) nor chronic exposure to $100 \mathrm{ppm}$ toluene influences the hepatic microsomal enzyme function in man as assessed by the antipyrine test.

If acute exposure to toluene for 6.5 hours had significantly changed the antipyrine clearance this effect should have expressed itself during the 24 hours immediatly after toluene exposure at a time when toluene was still present in considerable amounts in the liver and other lipid rich organs of the body. ${ }^{2}$ Studies have shown that the microsomal enzyme function recovers from environment or drug induced changes within a few days after the underlying cause has been eliminated from the body. ${ }^{1213}$
Since toluene is eliminated with a half life in blood of about eight hours and a half life in adipose tissue of one to two days, ${ }^{2}$ two weeks should suffice for the microsomal enzyme function to return to normal after a possible toluene induced change. If not this change should become apparent by differences between the first two antipyrine measurements and the last two performed about four and eight weeks later, respectively, or between that of the exposed and non-exposed individuals.

The residual variance of the decay of antipyrine in saliva from the self made antipyrine measurements among the subjects did not differ significantly from the corresponding values of the measurements performed under the control of laboratory technicians, indicating that the subjects managed to perform the antipyrine test correctly themselves.

The well established difference in antipyrine clearance between smokers and non-smokers of about $20 \%$ was reproduced in this study.

Supported by grants from the Danish Working Environment Fund.

\section{References}

' Cohr KH, Stockholm J. Toluene, a toxicologic review. Scand J Work Environ Health 1979;5:71-90.

${ }^{2}$ Carlsson A, Lindqvist T. Exposure of animals and man to toluene. Scand J Work Environ Health 1977;3:135-43. 
${ }^{3}$ Elovaara E, Savolainen H, Pfaffli P, Vainio H. Effects of subacute toluene inhalation on its metabolism and disposition in rat. Arch Toxicol 1979; suppl 2:345-8.

4 Ungvary GY, Manya S, Tatra E, et al. Effect of toluene inhalation on the liver of rats-dependence on sex, dose and exposure time. J Hyg Epidemiol Microbiol Immunol 1980;24:24252.

5 Toftgârd R, Gustavson J-Å. Biotransformation of organic solvents. Scand J Work Environ Health 1980;6:1-18.

- Edwards OM, Courtenay-Evans RJ, Galley JM, Hunter J, Tait AA. Changes in cortisol metabolism following rifampicin therapy. Lancet 1974;ii:549-51.

' Goss JE, Dickhaus DW. Increased bishydroxycoumarin requirements in patients receiving phenobarbital. $N$ Engl $J$ Med 1965;273:1094-5.

Jeffrey WH, Ahlin TA, Coren C, Hardy WR. Loss of warfarin effect after occupational insecticide exposure. JAMA 1976;236:2881-2.

- Baelum J, Lundquist GR, Mølhave L. Exposure to toluene. The effects on printing trade workers and control persons. Copenhagen: The Working Environment Fund, 1982.

${ }^{10}$ Døssing M. Antipyrine clearance during occupational exposure to styrene. $\mathrm{Br}$ J Ind Med 1983;40:224-8.

" Døssing M, Poulsen HE, Andreasen PB, Tygstrup N. A simple method for determination of antipyrine clearance. Clin Pharmacol Ther 1982;32:292-6.

${ }^{12}$ Ballinger B, Browning M, O'Malley K, Stevenson IH. Drug metabolizing capacity in states of drug dependence and withdrawal. Br J Pharmacol 1972;45:638-43.

${ }^{13}$ Toverud EL, Boobis AR, Brodie MJ. Differential induction of antipyrine metabolism by rifampicin. Eur J Clin Pharmacol 1981;21:155-60. 